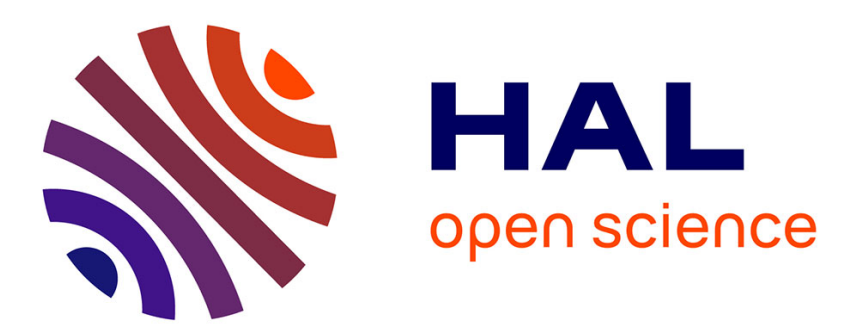

\title{
Simulation of heat pumps for simultaneous heating and cooling using $\mathrm{CO} 2$
}

\author{
Ahmadou Tidiane Diaby, Paul Byrne, Thierry Mare
}

\section{To cite this version:}

Ahmadou Tidiane Diaby, Paul Byrne, Thierry Mare. Simulation of heat pumps for simultaneous heating and cooling using CO2. International Journal of Refrigeration, 2019, 106, pp.616-627. 10.1016/j.ijrefrig.2019.03.010 . hal-02162139

\section{HAL Id: hal-02162139 \\ https://hal-univ-rennes1.archives-ouvertes.fr/hal-02162139}

Submitted on 21 Jun 2019

HAL is a multi-disciplinary open access archive for the deposit and dissemination of scientific research documents, whether they are published or not. The documents may come from teaching and research institutions in France or abroad, or from public or private research centers.
L'archive ouverte pluridisciplinaire HAL, est destinée au dépôt et à la diffusion de documents scientifiques de niveau recherche, publiés ou non, émanant des établissements d'enseignement et de recherche français ou étrangers, des laboratoires publics ou privés. 


\section{Highlights}

- A model of a CO2 heat pump is described

- A first model simulates a heat pump for simultaneous heating and cooling

- A second model simulates a heat pump for simultaneous cooling and desalination

- $\mathrm{CO} 2$ proposes new interesting applications for multi-function heat pumps

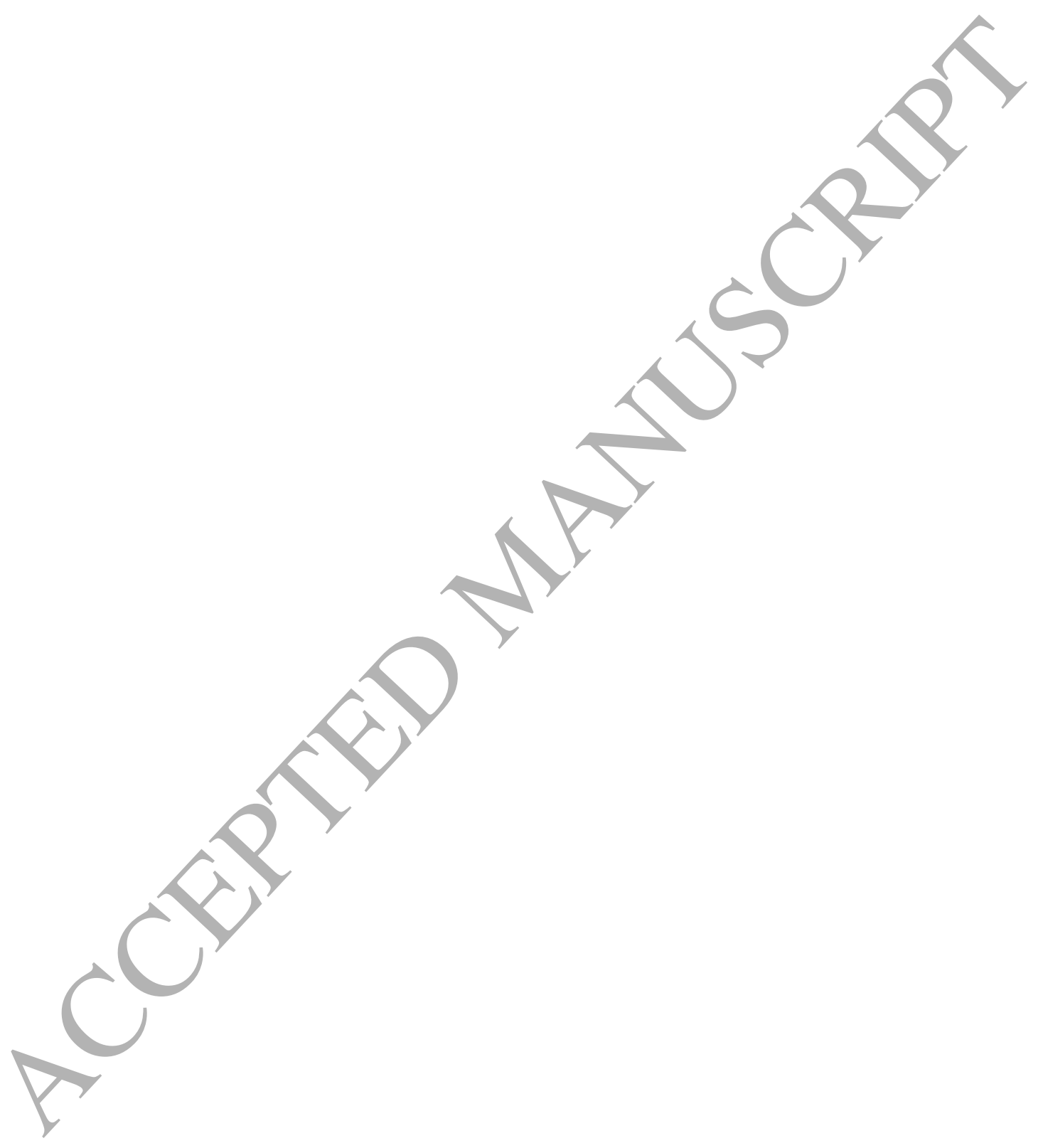




\title{
Simulation of heat pumps for simultaneous heating and cooling using $\mathrm{CO}_{2}$
}

\author{
Ahmadou Tidiane Diaby ${ }^{\mathrm{a}, \mathrm{b}}$, Paul Byrne ${ }^{\mathrm{a}^{*}}$, Thierry Maréa \\ ${ }^{a}$ Laboratoire Génie Civil Génie Mécanique, Université de Rennes, France \\ b Laboratoire d'Energétique Appliquée, Université Cheikh Anta Diop de Dakar, Sénégal
}

*corresponding author: paul.byrne@univ-rennes1.fr

LGCGM, Université de Rennes, France

IUT Génie Civil, 3 rue du Clos Courtel, BP 90422, 35704 Rennes Cedex 7, France

Tel: +33223234297

Fax: +33223234051

\begin{abstract}
This article presents the numerical model of a heat pump using $\mathrm{CO}_{2}$ in a transcritical cycle. Two systems are envisaged in this work: a heat pump for simultaneous heating, cooling and domestic hot water (HPS1) and a heat pump for simultaneous cooling and desalination (using heat) (HPS2). The simulation study uses EES and TRNSYS to assess the performance of two heat pumps in different applications and operating conditions. The simulations show interesting performance indicators: the seasonal COP for heating and cooling and the exergy efficiency for both systems. HPS2 producing cooling and desalination has a higher seasonal process exergy efficiency than HPS1 due to the interesting use of energy for the desalination application. The performance analysis presents a seasonal Coefficient of Performance (COP) between 2 and 3.
\end{abstract}

Keywords: simulation, heat pump, simultaneous, heating, cooling, desalination 


\section{Nomenclature}

A

AGMD

B

Bo

$\mathrm{c}$

COP

$\mathrm{Cp}$

$\mathrm{D}$

dh

DHW

$\mathrm{e}$

EES

Ex

Ex

$\mathrm{f}$

F

$\mathrm{g}$

$\mathrm{h}$

hc

hp

HP

HPS

HPS 1

HPS2

$\mathrm{J}$

LMTD

lp

M

MD

$\dot{m}$

$\mathrm{N}$

NTU

$\mathrm{Nu}$

$\mathrm{p}$

$\operatorname{Pr}$

Q

$\dot{Q}$

$\mathrm{R}$

$\operatorname{Re}$

$\mathrm{S}$

$\mathrm{S}$

$\mathrm{T}$

$\mathrm{t}$

$\mathrm{U}$

$\mathrm{V}$

We

$\mathrm{X}$

$\mathrm{X}_{0}$

$\mathrm{X}_{\mathrm{tt}}$ surface area $\left[\mathrm{m}^{2}\right]$

air gap membrane distillation

mass transfer coefficient $\left[\mathrm{kg} \cdot \mathrm{m}^{-2} \cdot \mathrm{h}^{-1} \cdot \mathrm{Pa}^{-1}\right]$

boiling number [-]

chemical concentration $\left[\mathrm{g} \cdot \mathrm{L}^{-1}\right]$

coefficient of performance [-]

specific heat $\left[\mathrm{J}^{\mathrm{kg}}{ }^{-1} \cdot \mathrm{K}^{-1}\right]$

thermal diffusivity of water vapour in air $\left[\mathrm{m}^{2} \cdot \mathrm{s}^{-1}\right]$

hydraulic diameter $[\mathrm{m}]$

domestic hot water

relative clearance volume [-]

Engineering Equation Solver

exergy $[\mathrm{J}]$

exergy rate [W]

friction factor [-]

intensification parameter [-]

acceleration of gravity $\left[\mathrm{m} \cdot \mathrm{s}^{-2}\right]$

specific enthalpy $\left[\mathrm{J} \cdot \mathrm{kg}^{-1}\right]$

convective heat transfer coefficient $\left[\mathrm{W} \cdot \mathrm{m}^{-2} \cdot \mathrm{K}^{-1}\right]$

high pressure [bar]

heat pump

heat pump for simultaneous heating and cooling

heat pump for simultaneous space heating, space cooling and DHW production

heat pump for simultaneous space cooling and desalination

permeate flux $\left[\mathrm{kg} \cdot \mathrm{s}^{-1} \cdot \mathrm{m}^{-2}\right]$

logarithmic Mean Temperature Difference $[\mathrm{K}]$

low pressure [bar]

molar mass $\left[\mathrm{kg} \cdot \mathrm{mol}^{-1}\right]$

membrane distillation

mass flow rate $\left[\mathrm{kg} . \mathrm{s}^{-1}\right]$

number of moles [mol]

number of heat transfer units [-]

Nusselt number [-]

pressure $[\mathrm{Pa}]$

Prandtl number [-]

thermal energy $[\mathrm{J}]$

thermal power [W]

gas constant $\left[\mathrm{J} . \mathrm{K}^{-1} \cdot \mathrm{mol}^{-1}\right]$

Reynolds number [-]

specific entropy $\left[\mathrm{J} \cdot \mathrm{kg}^{-1} \cdot \mathrm{K}^{-1}\right]$

correction parameter [-]

temperature $[\mathrm{K}]$

time [s]

overall heat transfer coefficient $\left[\mathrm{W} \cdot \mathrm{m}^{-2} \cdot \mathrm{K}^{-1}\right.$ ]

volume $\left[\mathrm{m}^{3}\right]$

Weber number [-]

quality [-]

correlation parameter [-]

Lockhart-Martinelli parameter [-] 


\section{Greek letters}

$\beta$

$\gamma_{\mathrm{i}}$

$\delta$

$\Delta$

$\varepsilon$

$\epsilon$

$\varphi$

$\eta$

$\lambda$

$\mu$

$\rho$

$\sigma$

$\tau$

$\chi$

\section{Subscripts}

0

bp

c

$\mathrm{cb}$

cd

el

ev

$\exp$

ex

is

in

inst

$\mathrm{g}$

$\mathrm{gc}$

$\mathrm{h}$

ic

1

$\mathrm{m}$

mec

$\mathrm{nb}$

out

opt

$\mathrm{p}$

$\mathrm{s}$

solv

sim

so

$\mathrm{v}$

vol heat transfer coefficient $\left[\mathrm{W} \cdot \mathrm{m}^{-2} \cdot \mathrm{K}^{-1}\right]$

correlation parameter

number of particles generated from the dissociation of species $i$

thicknesses [m]

difference

thermal efficiency [-]

porosity [\%]

thermal flux [W.m $\left.{ }^{-2}\right]$

efficiency [-]

thermal conductivity $\left[\mathrm{W} . \mathrm{m}^{-1} \cdot \mathrm{K}^{-1}\right]$

dynamic viscosity [Pa.s]

density $\left[\mathrm{kg} \cdot \mathrm{m}^{-3}\right]$

surface tension [N.m $\left.{ }^{-1}\right]$

tortuosity [-]

mole fraction [-]

reference state

bypass

cold

convective boiling

condenser/gas cooler outlet

electric

evaporator

experimental

exergy

isentropic

inlet

instantaneous

air gap

gas cooler

hot

$\mathrm{i}^{\text {th }}$ chemical component

liquid

membrane

mechanical

nucleate boiling

outlet

optimal

plate

swept

solvent

simulation

source

vapour

volumetric 


\section{Introduction}

After the 1930s, carbon dioxide $\left(\mathrm{CO}_{2}, \mathrm{R} 744\right)$ has undergone a long decline due to the preferred use of synthetic refrigerants. At the end of the $1990 \mathrm{~s}, \mathrm{CO}_{2}$ was revived thanks to its interesting properties and its very low impact on the environment. Gustav Lorentzen (1994) argued that carbon dioxide is the best fluid to replace CFCs and HCFCs. Carbon dioxide is a natural refrigerant with significant advantages such as non-toxicity, nonflammability, zero ozone depletion potential, interesting heat transfer properties, compatibility with usual lubricants, easy accessibility, low cost and high heating capacity (Haida et al., 2018). In the view of increasingly stringent regulations on greenhouse gases, carbon dioxide appeared again as an interesting fluid. It is proposed as a long-term substitute for environmental and personal safety reasons. According to Peter Nekså (2002), $\mathrm{CO}_{2}$ is a promising fluid, even for the application of building heating. Carbon dioxide is becoming well integrated in air conditioning and heat pump systems because the knowledge of its thermodynamic properties is now sufficient. Moreover, it is an abundant fluid in nature (Hu et al., 2015). Its unique features are a low critical temperature (31 ${ }^{\circ} \mathrm{C}$ ) and a relatively high critical pressure 73.8 bar. $\mathrm{CO}_{2}$ has a saturation pressure much higher than that of other fluids. In common cycles with $\mathrm{CO}_{2}$, the system high temperature is often greater than the critical temperature due to the temperature of the heat sink. The new components of this technology are increasingly adapted to the thermodynamic properties of $\mathrm{CO}_{2}$. In heating and cooling applications, the transcritical carbon dioxide cycle has no condensation process as in a conventional condenser. A supercritical gas is cooled in a so-called "gas cooler". In its state, supercritical gas resembles a viscous fog.

International research on $\mathrm{CO}_{2}$ cooling applications is active; several studies of the literature deal with this subject. Bansal (2012) reviews on the status of $\mathrm{CO}_{2}$ and he concludes that opportunities exist at low-temperature applications, especially in the food industry thanks to its harmless properties on the environment and cost competitiveness. For the same reasons, Ma et al. (2013) also announces a possible more common use of $\mathrm{CO}_{2}$ transcritical cycles. The use of $\mathrm{CO}_{2}$ in the promising supermarket sector was reviewed by Gullo et al. (2018). Chesi et al. (2012) has developed a test bench to study refrigeration cycles and equipment that work with this refrigerant. He showed that particular attention should be paid to the choice of components. Peñarrocha et al. (2014) proposed a model-free real-time optimization and control strategy for $\mathrm{CO}_{2}$ transcritical refrigeration plants that assures covering the cooling demand and continuous tracking of conditions for maximum efficiency. An analysis of the behaviour of a $\mathrm{CO}_{2}$ refrigeration system designed for supercritical conditions when operating under subcritical conditions is conducted by Sánchez et al. (2014). The results obtained in this work showed a decrease of the coefficient of performance (COP) and cooling capacity if the heat exchanger designed as a gas 
cooler operates as a condenser in some cases. Llopis et al. (2016) studied the impact of experimental mechanical sub-cooling system dedicated to a transcritical $\mathrm{CO}_{2}$ refrigeration system. It was found that the best improvements in terms of $\mathrm{COP}$ were obtained at high evaporating levels with high heat rejection temperatures. Therefore, a high capacity and domestic hot water (DHW) production are generally preferred for $\mathrm{CO}_{2}$.

Other areas for $\mathrm{CO}_{2}$ application are heating, domestic hot water and fresh water production. It is in this sense that Pitarch et al. (2016) analysed air-to-water heat pump two-stage cycles with R744 for heating applications up to $80{ }^{\circ} \mathrm{C}$, an interesting temperature for desalination. Fernandez et al. (2010) built a $\mathrm{CO}_{2}$ heat pump water heater and a performance evaluation was conducted to investigate the effect of ambient temperature and hot water temperature on the overall COP during full tank heating tests. The results obviously show that the overall COP was maximized at higher ambient temperatures and at lower hot water temperatures. They also investigated the use of a two-stage cycle and an internal heat exchanger that enhanced the coefficient of performance by 7.2 and $7.5 \%$ respectively. Jiang et al. (2013) studied a suitable heat exchanger to improve the efficiency of heat transfer and, therefore, improve the $\mathrm{COP}$ by presenting a water-to-water $\mathrm{CO}_{2}$ transcritical heat pump system. They reported that lowering the $\mathrm{CO}_{2}$ outlet temperature of the gas cooler is an important way to improve the system's performance. A constraints-free transcritical $\mathrm{CO}_{2}$ heat pump model for medium and large system applications is proposed by Sian et al. (2017). In this study, several relevant parameters such as water inlet temperature, plate geometry and the number of internal heat exchanger plates were conducted to examine their influence on the system's performance. They showed that as the number of plates increases, the internal heat exchanger engenders a significant improvement of about $12 \%$ on the system's COP.

In the literature, other research projects focus on the simultaneous production of heat and cooling using $\mathrm{CO}_{2}$ as a refrigerant. White et al. (1997) present the advantageous performance of a transcritical $\mathrm{CO}_{2}$ heat pump for simultaneous refrigeration and water heating. An economic optimum heating COP in excess of 3.0 was obtained. Agrawal and Bhattacharyya (2011) used transcritical $\mathrm{CO}_{2}$ for the simultaneous production of heating and cooling with a $\mathrm{COP}$ up to 3.7. The performance of a transcritical $\mathrm{CO}_{2}$ booster refrigeration system is presented by Sawalha (2013) to cover the simultaneous cooling and heating needs in an average size supermarket in Sweden. This study concluded that energy consumption is slightly lower in an average size supermarket compared to the conventional refrigeration system with a separate heat pump for heating needs. The cumulative COP of simultaneous heating and cooling nearly reaches 6 . A combined air conditioning and tap water heating plant using carbon dioxide as refrigerant has been investigated theoretically by Adriansyah (2004). The system, 
achieving a highest total-COP of 8 , is suitable for countries with year-round cooling demand, such as Indonesia or Singapore, and a demand for hot tap water. Recently, Liu et al. (2016) also proposed a transcritical $\mathrm{CO}_{2}$ heat pump able to provide simultaneous heating and cooling. The main conclusion of their study is that the heating and cooling capacities have to respect an ideal ratio of 1.45 to fully utilize the heat pump in their food process. This ratio maximizes the operating time in the simultaneous mode. Farsi et al. (2016) realized a combination of transcritical carbon dioxide refrigeration with a multi-effect desalination system to provide cold water and fresh water simultaneously. They benefited from the high transcritical $\mathrm{CO}_{2}$ heat exchange coefficient to reduce the heat transfer area.

The literature review about cooling, heating and simultaneous heating and cooling applications shows promising trends for carbon dioxide. $\mathrm{CO}_{2}$ can become an advantage for multi-function heat pumps that are usually perceived as complex systems. With $\mathrm{CO}_{2}$, the perception of complexity can be diluted by the information of the use of a "very special" refrigerant. Reciprocally, a multi-function heat pump can become interesting with $\mathrm{CO}_{2}$. Indeed, the continuous variation of $\mathrm{CO}_{2}$ temperature in the gas cooler of the transcritical cycle between about 120 and $20^{\circ} \mathrm{C}$ can be used to produce hot water at a higher temperature than with standard heat pumps.

This study presents the general equations of a model of a $\mathrm{CO}_{2}$ heat pump in two case studies. The first study deals with a heat pump for simultaneous heating and cooling (HPS1) that produces hot, cold and domestic hot water (DHW) for buildings in Europe. The second heat pump for simultaneous cooling and desalination (HPS2) carries out cooling and desalination for buildings for hot regions of the world. The objective is to show the different applications of a $\mathrm{CO}_{2}$ heat pump for multi-functional uses. The simulation study using EES (Engineering Equation Solver) (Klein, 2017) and TRNSYS (SEL, 2010) evaluates the performance of the two heat pumps for different operating conditions.

\section{General modelling assumptions}

The numerical study is carried out using an EES-TRNSYS interface. TRNSYS model Type66c allows the dialogue between EES and TRNSYS. Fig. 1 is a screenshot of the representation of the modelling of HPS1 and HPS2. This modelling is a compilation of several models from TRNSYS and EES. For the simulation of HPS1, only the model of the heat pump is developed with EES. EES, Engineering Equation Solver, is a software for solving non-linear equation systems that includes internal functions retrieving thermodynamic properties of fluids. In the case of HPS2, the model of the desalination unit is developed with EES and is connected to the condenser to heat the seawater instead of domestic hot water or premises such as in the case of HPS1. An 
optimum pressure is calculated and implemented in the transcritical $\mathrm{CO}_{2}$ heat pump models. Dynamic thermal simulations of buildings call typical meteorological files to study the evolution of the energy production and consumption yearly. The building model represents a 2-storey hotel.

Each component of the machine is a model programmed in EES. The modelling of the heating and cooling device consists in linking the unit models of the elements that compose it one after the other. The input variables of each basic model of the heat pump are the outlet variables of the previous model. The general modelling assumptions are a 1D configuration in the desalination unit and a succession of steady states for the heat pump model.

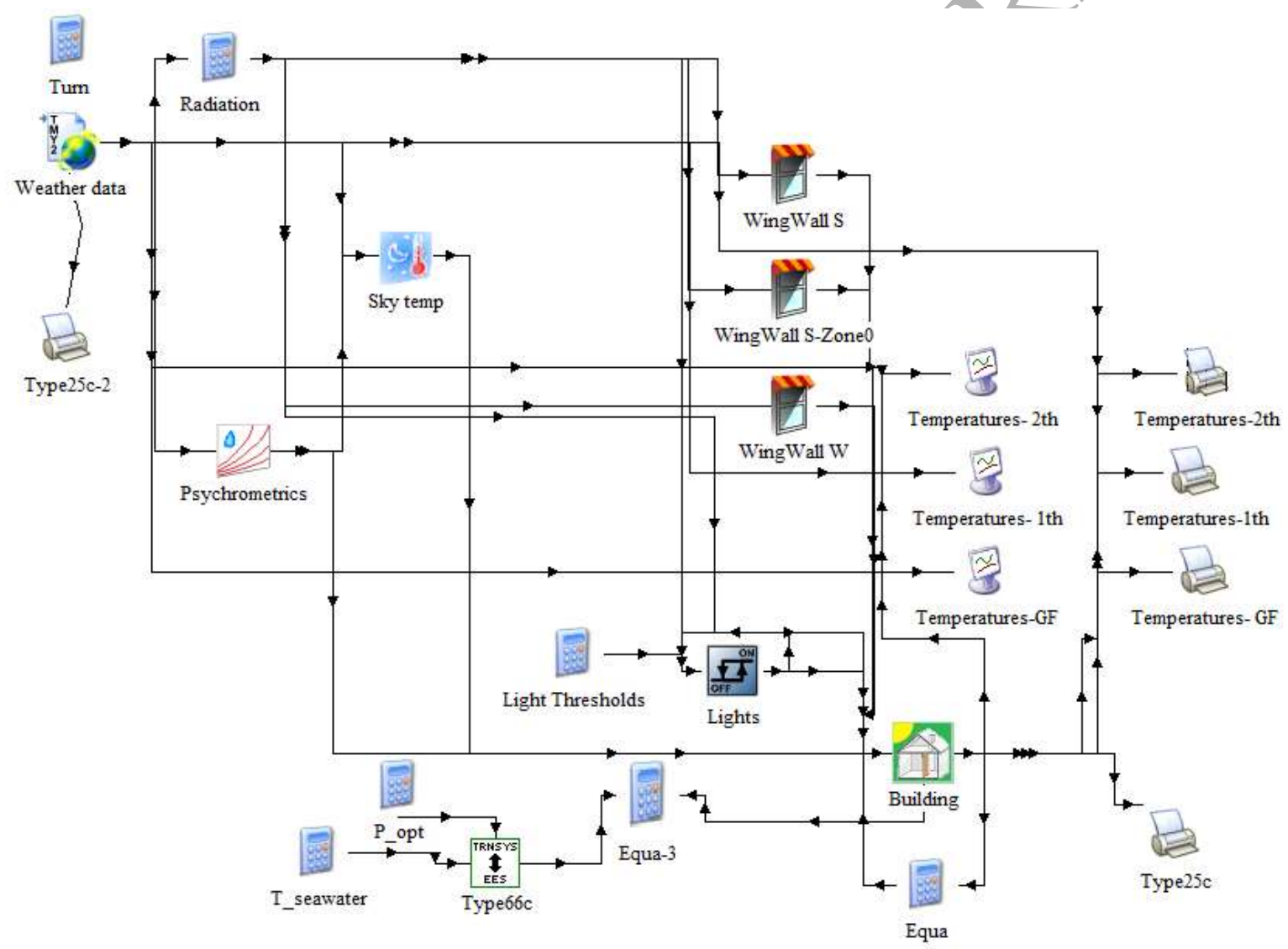

Figure 1: Scheme of the simulation of the $\mathrm{CO}_{2} \mathrm{HPS}$ coupled to a building and the desalination system

The key performance indicators of the HPS coupled to a building are the coefficient of performance (COP) and the exergy efficiency $\left(\eta_{\text {ex }}\right)$. The instantaneous and seasonal or integrated COP given in Eq. (1) and Eq. (2) correspond to the global thermal capacities or energies produced in heating and cooling over the electric power or energy absorbed by the HPS, including auxiliaries (pumps and fans). 
$C O P_{\text {inst }}=\frac{\text { Thermal capacity }}{\text { Electric power }}$

$C O P_{\text {seasonal }}=\frac{\sum_{8760 h} \text { Thermal energy produced }}{\sum_{8760 h} \text { Electric energy absorbed }}$

The instantaneous (and seasonal) exergy efficiency is defined in Eq. (3) (and Eq. (4)) as the ratio of the sum of exergy rate $(E x)$ outputs (exergy amounts $(E X)$ produced in Eq. (4)) over the sum of the exergy rate inputs (and exergy consumed in Eq. 4).

$\eta_{\text {ex-inst }}=\frac{\sum \dot{E} x_{\text {out }}}{\sum \dot{E} x_{\text {in }}}$

$\eta_{\text {ex-seasonal }}=\frac{\sum \mathrm{Ex}_{\text {out }}}{\sum \mathrm{Ex}_{\text {in }}}$

Exergy is used to evaluate the irreversibilities of the processes. The exergy rate $(E x)$ is given by Eq. (5). Exergy destruction is by definition non-existent during a reversible process and a part of the exergy is destroyed during an irreversible one. The exergy rate through the different thermal processes of the heat pump cycle use the Carnot efficiency, calculated with the ambient temperature $\mathrm{T}_{0}$ and the mean logarithmic source temperature $\overline{T_{s o}}$, and a quantity of thermal capacity $(\dot{\mathrm{Q}})(\mathrm{Eq} .(6))$.

$\dot{E x}=\dot{m}\left[\left(h-h_{0}\right)-T_{0}\left(s-s_{0}\right)\right]$

$\dot{E} x_{t h}=\dot{\mathrm{Q}}\left|1-\frac{T_{0}}{\overline{T_{s o}}}\right|$

The exergy rate of water flows containing chemical substances are evaluated using Eq. (7) (Macedonio and Drioli, 2010), where $N_{\text {solv }}$ is the number of moles of solvent (Eq. (8)) and $\chi_{\text {solv }}$ is its mole fraction (Eq. (9)).

$$
\begin{aligned}
& \dot{E x_{w}}=\dot{m} \cdot\left[C p \cdot\left(T-T_{0}\right)-C p \cdot T_{0} \cdot \ln \left(\frac{T}{T_{0}}\right)+\frac{p-p_{0}}{\rho}-N_{\text {solv }} \cdot R \cdot T_{0} \cdot \ln \chi_{\text {solv }}\right] \\
& N_{\text {solv }}=\frac{1000-\sum \frac{c_{i c}}{\rho}}{M_{\text {solv }}} \\
& \chi_{\text {solv }}=\frac{N_{\text {solv }}}{N_{\text {solv }}+\sum\left(\frac{\gamma_{i c} c_{i c}}{\rho \cdot M_{i c}}\right)}
\end{aligned}
$$




\section{Simulation of HPS1: a heat pump for simultaneous space heating, space cooling and DHW production}

\subsection{Presentation of HPS1}

The first heat pump for simultaneous heating and cooling was designed for space heating, space cooling and DHW production for hotels, office buildings or residential collective buildings. Fig. 2 shows the refrigeration circuit of HPS1. HPS1 can operate under three modes: heating only, cooling only and simultaneous modes. The electronic valves (Evr) are switched on or off to select the desired operating mode. The water condenser and the water evaporator are plate heat exchangers that produce hot and cold water respectively. A balancing air heat exchanger operates either as a condenser for heat rejection in a cooling mode or as an evaporator for heat suction in a heating mode. It is not used in the simultaneous mode.

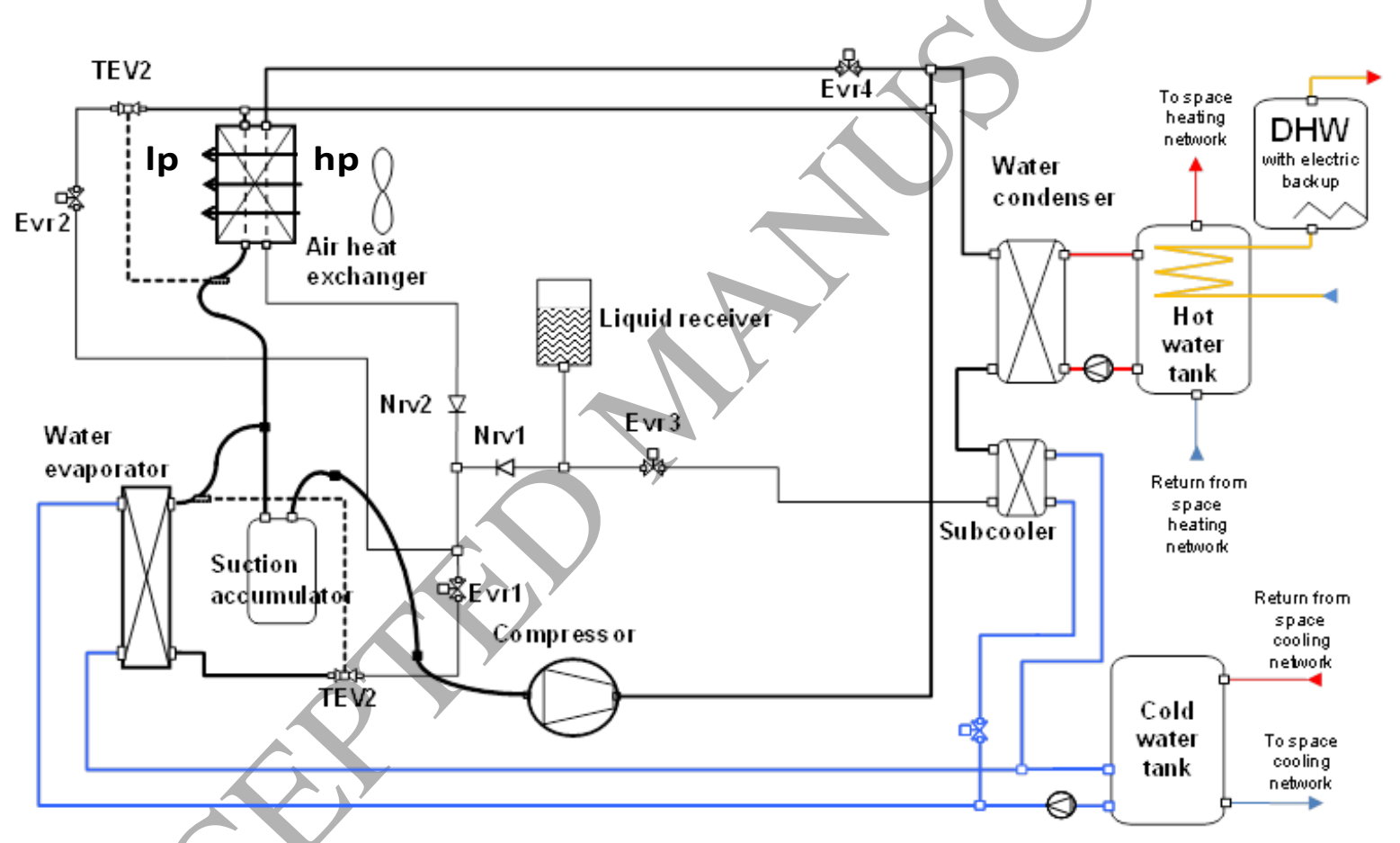

Figure 2: HPS1 refrigeration circuit

A prototype of $15 \mathrm{~kW}$ heating capacity using refrigerant $\mathrm{R} 407 \mathrm{C}$ was built and tested under the conditions of standard EN 14511 in a climatic chamber (European Standard, 2013). A numerical model was validated using the experimental results and modified for $\mathrm{CO}_{2}$. A performance table was created for a HPS using R407C or $\mathrm{CO}_{2}$ as a working fluid. The components of the HPS were modelled and assembled to simulate different refrigeration cycles. Simulations were run using EES software to establish performance tables giving heating and cooling capacities as well as the electric power depending on heat source and heat sink temperatures. These performance 
tables were used in the final heat pump model coupled to a 45-bedroom hotel in the TRNSYS environment (detailed in section 3.2.3.).

\subsection{Specific modelling assumptions}

\subsubsection{Compressor model}

The compressor model calculates the mass flow rate $\dot{m}$ and the compression mechanical power $\dot{W}$ knowing the input and output pressures (Eqs (10), (11), (12) and (13)). The output pressure is set by the high pressure control system. Isentropic efficiency is chosen constant and equal to 0.8 for carbon dioxide and to 0.7 for $\mathrm{R} 407 \mathrm{C}$. Isentropic efficiency is higher for $\mathrm{CO}_{2}$ thanks to the lower compression ratio. The relative clearance volume $e$ is taken constant equal to $2 \%$. Mechanical and electrical efficiencies $\left(\eta_{m e c}\right.$ and $\left.\eta_{e l}\right)$ are taken constants and equal to 0.8 and 0.95 .

$\dot{m}=\rho \cdot \eta_{v o l} \cdot V_{s}$

Where $\rho$ is the density, $\eta_{v o l}$ is the volumetric efficiency defined in Eq. (11) and $V_{S}$ is the swept volume.

$\eta_{v o l}=1-e \cdot\left[\left(\frac{h p}{l p}\right)^{\frac{1}{n}}-1\right]$

Where $e$ is the relative clearance volume, $h p$ and $l p$ are high and low pressures and $n$ is the polytropic coefficient.

$\dot{W}_{i s}=\frac{n}{n-1} \cdot l p \cdot \eta_{v o l} \cdot V_{s} \cdot\left[\left(\frac{h p}{l p}\right)^{\frac{n-1}{n}}-1\right]$

$\dot{W}=\frac{\dot{W}_{i s}}{\eta_{i s} \cdot \eta_{m e c} \cdot \eta_{e l}}$

Finally, the discharge temperature is calculated thanks to the database of refrigerant properties available in EES for the outlet values of enthalpy (Eq. (14)) and high pressure.

$h_{\text {out }}=h_{\text {in }}+\frac{h_{\text {out }- \text { ideal }}-h_{\text {in }}}{\eta_{\text {is }}}$

The optimal high pressure for the transcritical $\mathrm{CO}_{2}$ thermodynamic cycle is set depending on the evaporating and gas cooler outlet temperatures $\left(T_{e v}\right.$ and $\left.T_{g c-o u t}\right)$ following Eq. (15) (Yang et al., 2015).

$P_{\text {opt }}=3.065 \cdot T_{g c-o u t}+0.36 \cdot T_{e v}-0.0153 \cdot T_{e v} \cdot T_{g c-o u t}-20.33$ 


\subsubsection{Heat exchanger models}

Heat exchanger models are classic models using the LMTD (Logarithmic Mean Temperature Difference) and NTU- $\varepsilon$ (Number of Transfer Units - efficiency). They calculate the evaporating and condensing pressure and the outlet temperatures of the sources (hot and cold) depending on the dimensions of heat exchangers and on the operating parameters. A discretization into 50 sections was used to better take into account the variations of properties of the fluids. The pressure drop was neglected. No internal heat exchanger was modelled for $\mathrm{CO}_{2}$.

The models of tube-and-fins evaporators are similar for R407C and $\mathrm{CO}_{2}$. They use the LMTD (Eq. 16) and the energy balance (Eqs. 17 and 18) to converge and determine the outlet temperatures of air and refrigerant. Two sections are modelled: the two-phase and the superheating regions. A $5 \mathrm{~K}$ superheating degree is assumed to be controlled by the expander.

$\dot{Q}=U \cdot A \cdot L M T D$

$\dot{Q}=\dot{m} \cdot C p \cdot \Delta T$

$\dot{Q}=\dot{m} \cdot \Delta h$

The model of R407C condenser comprises three sections: the superheating, the condensation and the subcooling regions. To be able to converge, the model needs additional equations in the subcooling region to determine the outlet temperature. Eq. 19 defines the number of heat transfer units, Eq. (20) determines the efficiency and Eq. 21 calculates the heat transfer rate depending on the efficiency, the minimum product of mass flow rate and specific heat $\dot{m} C p_{\min }$ and the difference between inlet temperatures of hot and cold fluids.

$$
\begin{aligned}
& N T U=\frac{U \cdot A}{\dot{m} C p_{\min }} \\
& \varepsilon=\frac{1-\exp \left(-N T U \cdot\left(1-\frac{\dot{m} C p_{\text {min }}}{\dot{m} C p_{\max }}\right)\right)}{1-\frac{\dot{m} C p_{\min }}{\dot{m} C p_{\max }} \exp \left(-N T U \cdot\left(1-\frac{\dot{m} C p_{\min }}{\dot{m} C p_{\max }}\right)\right)} \\
& \dot{Q}=\varepsilon \cdot \dot{m} C p_{\text {min }} \cdot\left(T_{h-i n}-T_{c-i n}\right)
\end{aligned}
$$

The model of $\mathrm{CO}_{2}$ gas cooler only utilizes the NTU- $\varepsilon$ equations because Eq. (15) gives the optimal pressure. For other heat exchangers, the pressure is an output of the model. It corresponds to the pressure that enables to solve the equation system with given inlet conditions and dimensions. To calculate the U-values (overall heat transfer coefficients), correlations from the literature were applied. The correlations are given in table 1 
depending on the heat transfer type and the refrigerant. The Mc Adams correlation is used for sensible heat transfer of secondary fluids or refrigerant in superheating, desuperheating and subcooling processes.

Table 1: Correlations for heat transfer coefficients

\begin{tabular}{|c|c|c|}
\hline Heat transfer type & Author & Equations \\
\hline Sensible & Mc Adams (ASHRAE, 1989) & $\begin{array}{l}N u=0.023 \operatorname{Re}^{0.8} \operatorname{Pr}^{0.4} \text { if fluid is heated } \\
N u=0.023 \operatorname{Re}^{0.8} \operatorname{Pr}^{0.3} \text { if fluid is cooled }\end{array}$ \\
\hline Evaporation of R407C & Tran et al., 1996 & $h c=8.4 \cdot 10^{5} \cdot\left(B o^{2} W e_{l}\right)^{0.3}\left(\frac{\rho_{l}}{\rho_{v}}\right)^{-0.4}$ \\
\hline Condensation of R407C & Mc Adams (ASHRAE, 1989) & $h c=0.0077 \cdot\left(\lambda^{3} \rho^{2} g\right)^{0.33} \frac{R e^{0.4}}{\mu^{0.67}}$ \\
\hline Evaporation of $\mathrm{CO}_{2}$ & $\begin{array}{l}\text { Benett-Chen (1980) modified } \\
\text { by Hwang et al. (1997) }\end{array}$ & 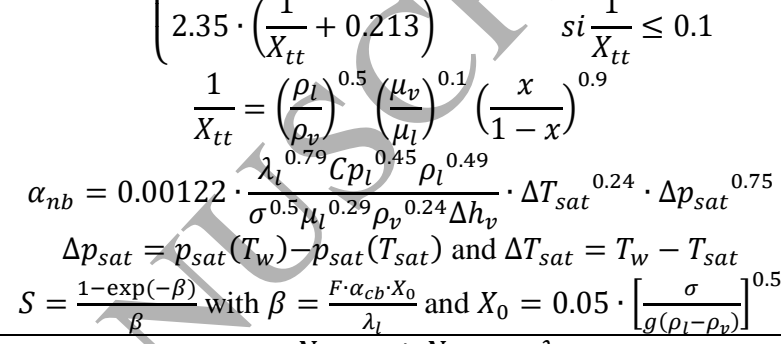 \\
\hline $\mathrm{CO}_{2}$ gas cooling & $\begin{array}{l}\text { Pittla et al. (2002) } \\
\text { Gnielinski (1976) }\end{array}$ & $\begin{aligned} N u & =\left(\frac{N u_{\text {wall }}+N u_{\text {bulk }}}{2}\right) \frac{\lambda_{\text {wall }}}{\lambda_{\text {bulk }}} \\
N u_{\text {local }} & =\frac{(f / 8)(R e-1000) P r}{1+12.7(f / 8)^{1 / 2}\left(\operatorname{Pr}^{2 / 3}-1\right)}\end{aligned}$ \\
\hline
\end{tabular}

The characteristics of the modelled heat exchangers are given in table 2. Due to the higher heat transfer coefficients of $\mathrm{CO}_{2}$, the heat transfer surface area of the water $\mathrm{CO}_{2}$ gas cooler is smaller than the one of the R407C condenser and the hydraulic diameter for $\mathrm{CO}_{2}$ tubes is smaller. The water and air heat exchangers are supposed to be plate heat exchangers and finned tube heat exchangers respectively.

Table 2: Heat exchangers characteristics

\begin{tabular}{|c|c|c|c|c|}
\hline Refrigerant & Secondary fluid & $\begin{array}{c}\text { Heat } \\
\text { exchanger }\end{array}$ & $\begin{array}{c}\text { Heat transfer surface } \\
\text { area }\left(\mathrm{m}^{2}\right)\end{array}$ & $\begin{array}{c}\text { Hydraulic diameters ( } \mathrm{mm}) \\
\text { Refrigerant / Secondary fluid }\end{array}$ \\
\hline \multirow{2}{*}{$\mathrm{R} 407 \mathrm{C}$} & \multirow{2}{*}{ Water } & Condenser & 2.45 & $3.9 / 3.9$ \\
\hline & & Evaporator & 0.8 & $3.9 / 3.9$ \\
\hline \multirow{2}{*}{$\mathrm{R} 407 \mathrm{C}$} & \multirow{2}{*}{ Air } & Condenser & 4.24 & $10 / 3.4$ \\
\hline & & Evaporator & 4.24 & $10 / 3.4$ \\
\hline & \multirow{2}{*}{ Water } & Gas cooler & 0.6 & $1 / 3.9$ \\
\hline $4 U_{2}$ & & Evaporator & 0.8 & $3.9 / 3.9$ \\
\hline \multirow{2}{*}{$\mathrm{CO}_{2}$} & \multirow{2}{*}{ Air } & Gas cooler & 4.24 & $10 / 3.4$ \\
\hline & & Evaporator & 4.24 & $10 / 3.4$ \\
\hline
\end{tabular}

Table 3 presents the orders of magnitude of heat transfer coefficients (hc values) calculated with the correlations given in table 1 . They may slightly vary depending on temperature. The values for air are of the order of magnitude of $100 \mathrm{~W} \cdot \mathrm{m}^{-2} \cdot \mathrm{K}^{-1}$ whereas for water, they vary between 9000 and $15000 \mathrm{~W} \cdot \mathrm{m}^{-2} \cdot \mathrm{K}^{-1}$ 
depending on the type of heat exchanger. The difference is compensated by the heat transfer area. In condensation for $\mathrm{R} 407 \mathrm{C}$, the hc coefficients are around $30000 \mathrm{~W} \cdot \mathrm{m}^{-2} \cdot \mathrm{K}^{-1}$. For $\mathrm{CO}_{2}$, the coefficients reach 7000 $\mathrm{W} . \mathrm{m}^{-2} \cdot \mathrm{K}^{-1}$ around the critical point. In evaporation, the exchange coefficients reach $20000 \mathrm{~W} \cdot \mathrm{m}^{-2} \cdot \mathrm{K}^{-1}$ for $\mathrm{R} 407 \mathrm{C}$ and $40000 \mathrm{~W} \cdot \mathrm{m}^{-2} \cdot \mathrm{K}^{-1}$ for the $\mathrm{CO}_{2}$. These values justify the dimensions of heat exchangers. The accuracy of the $\mathrm{CO}_{2}$ model is dependent on the correlations used. Pittla et al. (2002) proves that their results with their correlation are within an error of $\pm 20 \%$ for $85 \%$ of the values. All correlations try to stay within this interval.

Table 3: Order of magnitude of heat transfer coefficients

\begin{tabular}{|c|c|c|c|}
\hline \multirow{2}{*}{ Fluid } & \multirow{2}{*}{$\begin{array}{c}\text { Heat } \\
\text { exchanger }\end{array}$} & \multicolumn{2}{|c|}{ Heat transfer coefficient $\left(W \cdot m^{-2} \cdot K^{-1}\right)$} \\
\hline & & Phase change & Sensible \\
\hline \multirow{2}{*}{$\mathrm{R} 407 \mathrm{C}$} & Condenser & 30000 & 1000 \\
\hline & Evaporator & 20000 & 1000 \\
\hline \multirow{2}{*}{$\mathrm{CO}_{2}$} & Gas cooler & - & \\
\hline & Evaporator & 40000 & \\
\hline $\begin{array}{c}\text { Water } \\
\text { Air }\end{array}$ & All & - & 10000 \\
\hline
\end{tabular}

\subsubsection{Case study}

Table 4 presents the annual demands in space heating, space cooling and DHW production of a hotel of 45 bedrooms located in Rennes (Fig. 3). The evolution of thermal needs over a year is presented in Fig. 4. The building was divided into 30 thermal zones depending on the orientation and the usage of the zone. The U-values of walls are around $0.3 \mathrm{~W} \cdot \mathrm{m}^{-2} \cdot \mathrm{K}^{-1}$. The argon-filled double glazings have a Ug-value of $1.4 \mathrm{~W} \cdot \mathrm{m}^{-2} \cdot \mathrm{K}^{-1}$. The infiltration rate is supposed constant and equal to $0.1 \mathrm{vol} / \mathrm{h}$. Mechanical ventilation renews the air at a rate of 0.6 $\mathrm{vol} / \mathrm{h}$ in the bedrooms. Internal gains are modelled through occupation ( 1 person per bedroom from 20:00 to 7:00; 12 persons in the common rooms from 8:00 to 18:00), lighting (from 20:00 to 23:00 in bedrooms, during occupation if the solar radiation is low in common rooms) and electric appliances (same scenario as occupation). The simulations are run using TRNSYS software with a time step of 5 minutes. The DHW demands are calculated daily assuming a consumption of $100 \mathrm{~L}$ per day and per bedroom of water at $50{ }^{\circ} \mathrm{C}$. The cold-water temperature is dependent on the season and is calculated by TRNSYS type 810.

Table 4: Annual needs of a 45-bedroom hotel in Rennes

\begin{tabular}{cc}
\hline Sectors & Annual needs \\
\hline DHW production & $74870 \mathrm{kWh} /$ year \\
Space heating & $51680 \mathrm{kWh} /$ year \\
Space cooling & $39184 \mathrm{kWh} /$ year \\
\hline
\end{tabular}




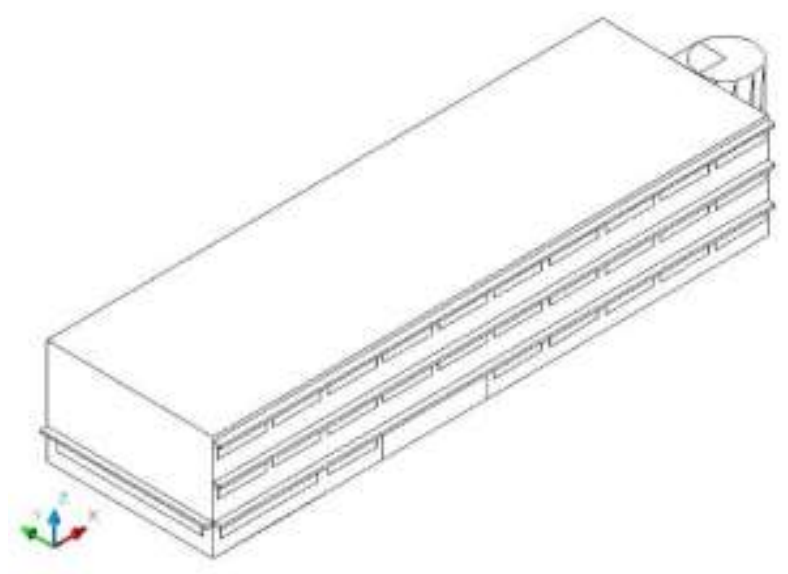

Figure 3: Isometric view of the 45-bedroom hotel

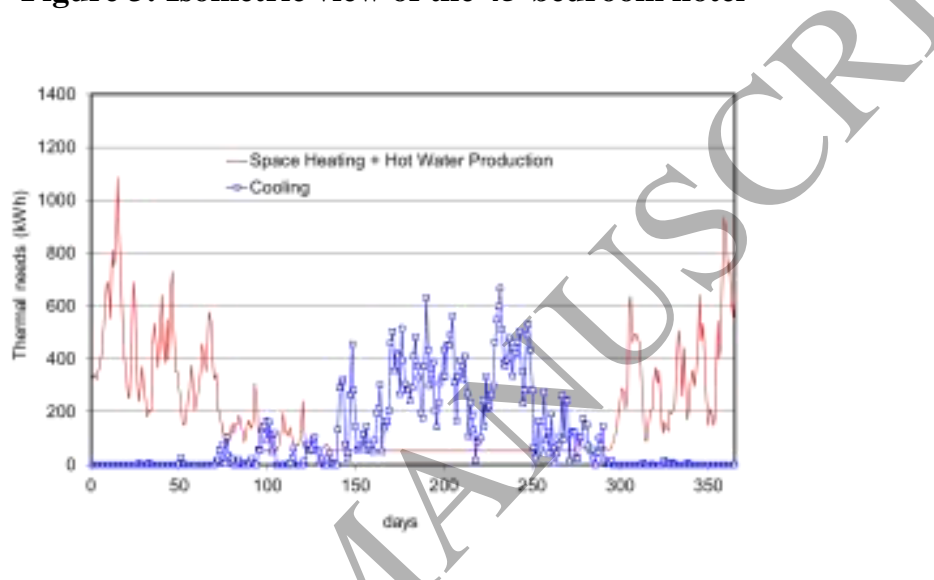

Figure 4: Evolution of thermal needs in heating and cooling of a 45-bedroom hotel

In the HPS model following Fig. 2, the heating capacity devoted to DHW production is deducted from the total heating capacity of the HPS. An electric backup is also implemented to the model in case the HPS cannot satisfy the DHW production on its own. The chosen hypothesis is that the use of a desuperheater (modelled upstream of the condenser for the simulation study) does not induce any change in the set point for high pressure compared to what it would be without DHW production.

The defrosting of the HPS is supposed « automatically » carried out during a simultaneous mode by a twophase thermosiphon. During a heating operation, some energy is recovered in the cold water tank by subcooling the refrigerant after condensation. This energy amount is used subsequently in a simultaneous mode as a heat source. The air evaporator is now free for defrosting. A part of the vapour created in the water evaporator naturally goes up to the air evaporator being a cold point for the refrigerant circuit. The refrigerant condenses and returns back to the water evaporator by gravity. This behaviour is described in detail in reference (Byrne et al., 2011). 


\subsection{Simulation results}

\subsubsection{Performance validation}

Table 5 shows the results of experimental and simulated exergy efficiencies for special operating points in the heating mode with R407C. Exergy efficiencies increase when the difference between heat source and heat sink temperatures increases. This is due to the relatively high increase of Carnot factor with respect to the decrease of COP. Good accordance can be observed between experimental and simulated results. The complete model has been validated in terms of performance on the complete range of operating conditions. The rest of the results can be found in Byrne et al. (2009). The relative difference between simulated and experimental results is within $5 \%$.

Table 5: Comparison of simulation and experimental results with HPS1 during a heating mode

\begin{tabular}{cccccc}
\hline $\boldsymbol{T}_{\boldsymbol{e v}}$ & $\boldsymbol{T}_{\boldsymbol{c d}}$ & $\boldsymbol{T}_{\text {air }}$ & $\boldsymbol{\eta}_{\text {ex-exp }}$ & $\boldsymbol{\eta}_{\text {ex-sim }}$ & $\begin{array}{c}\text { Relative } \\
\text { error }\end{array}$ \\
\hline $5^{\circ} \mathrm{C}$ & $35^{\circ} \mathrm{C}$ & $12.6^{\circ} \mathrm{C}$ & $22.3 \%$ & $23.3 \%$ & $4.5 \%$ \\
\hline $0^{\circ} \mathrm{C}$ & $40^{\circ} \mathrm{C}$ & $8.7^{\circ} \mathrm{C}$ & $32.6 \%$ & $31.2 \%$ & $-4.3 \%$ \\
\hline$-5^{\circ} \mathrm{C}$ & $45^{\circ} \mathrm{C}$ & $5.6^{\circ} \mathrm{C}$ & $35.7 \%$ & $34.7 \%$ & $-2.8 \%$ \\
\hline
\end{tabular}

\subsubsection{Simulation results during a winter sequence}

This section of the article presents the simulation results of exergy efficiencies and COPs of the R407C and $\mathrm{CO}_{2}$ HPSs during a winter heating sequence (Fig. 5). The winter sequence chosen corresponds to the evening of January $13^{\text {th }}$ (between 16:00 and 22:30) of the TRNSYS weather data file of Rennes. During this sequence, the ambient temperature decreases from $2.0^{\circ} \mathrm{C}$ to $-0.9^{\circ} \mathrm{C}$.

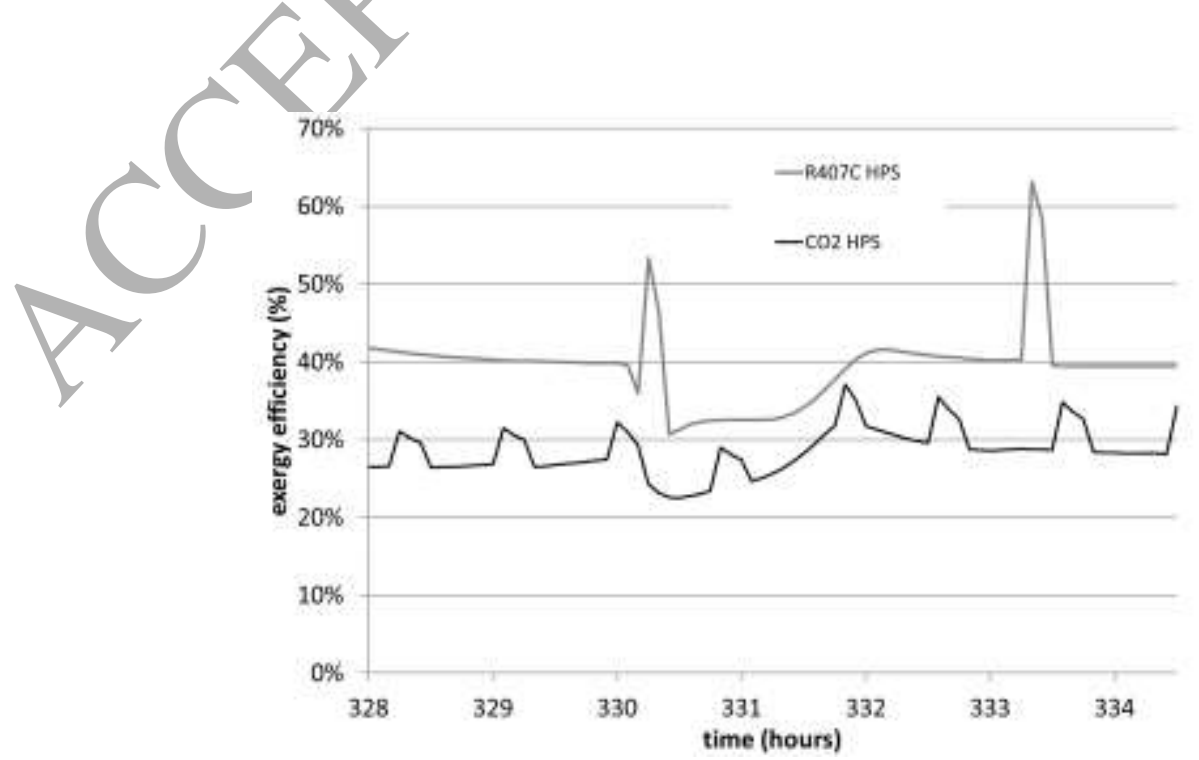

Figure 5: Evolution of exergy efficiency during a winter sequence 
The exergy efficiency increases when the simultaneous mode is switched on. Exergy efficiencies are much higher with $\mathrm{R} 407 \mathrm{C}$ than with $\mathrm{CO}_{2}$. Nevertheless, the peaks are much more numerous with $\mathrm{CO}_{2}$. HPS plants exhibit peaks in exergy efficiency during the use of simultaneous mode. This improvement is higher for the HPS using R407C. However, the number of changeovers from heating to simultaneous modes is more important for the HPS with $\mathrm{CO}_{2}$ (7 changeovers for $\mathrm{CO}_{2}$ and 2 for $\left.\mathrm{R} 407 \mathrm{C}\right)$. This behaviour comes from the difference between the amounts of recoverable energy by subcooling of the refrigerant. For $\mathrm{CO}_{2}$, this amount of energy is higher. The cold water tank temperature increases faster. Therefore, the changeover to the simultaneous mode is carried out earlier for $\mathrm{CO}_{2}$ than for $\mathrm{R} 407 \mathrm{C}$.

The period between the hours 330 and 332 corresponds to the interval 18:00 to 20:00 of January 13th. During this 2-hour period, a demand in DHW appears. This extra demand provokes a performance loss in terms of exergy efficiency.

During a sequence, the integrated COP will be higher than the one obtained with an operation in a heating mode only. A previous energy and exergy analysis showed that these sequences were interesting, leading to increases of 0.3 point on the annual COP and $6 \%$ on the exergy effíciency (2012).

Table 6 presents the coefficients of performance and exergy efficiencies, in heating mode, in simultaneous mode and in average during the winter sequence shown in Figure 4. The average value is calculated in proportion to the heating demand for each time step.

Table 6: Comparison of performance during a winter sequence

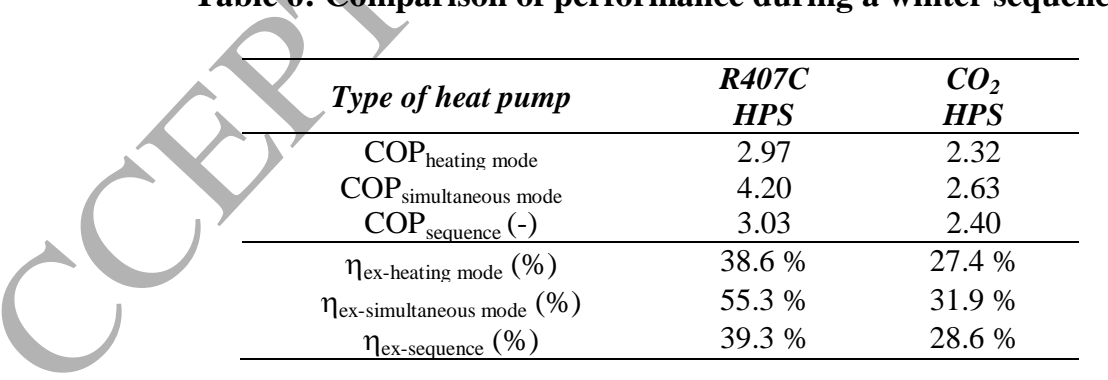

Taking into account the auxiliary heaters for space heating and DHW production, the energy performance assessed by the COP is lower (Table 7). The extra energy provided by the electric auxiliary directly corresponds to the amount of exergy produced by the auxiliary heater. Therefore, exergy efficiency increases in proportion to the use of backup heating for DHW production. 
Table 7: Performance comparison taking into account the backup consumptions during a winter sequence

\begin{tabular}{ccc}
\hline Type of heat pump & $\boldsymbol{R 4 0 7 C}$ & $\boldsymbol{C O}_{2}$ \\
& $\boldsymbol{H P S}$ & $\boldsymbol{H P S}$ \\
\hline $\mathrm{COP}_{\text {sequence }}$ including backups (-) & 2.57 & 1.90 \\
$\eta_{\text {ex-sequence }}$ including backups (\%) & $44.5 \%$ & $46.6 \%$ \\
\hline
\end{tabular}

\subsubsection{Simulation results depending on the season}

Table 8 presents the operating times in each mode and the performance comparison depending on the season for the R744 HPS1 system. The winter period is defined in this simulation by the first and last two months of the typical year, corresponding to hours from 1 to 1460 and from 7301 to 8760 . During winter, the simultaneous mode is not used for cooling but for improving the performance in heat production. Therefore, the cold production is not counted in the simultaneous mode COP. The cooling mode is switched on only 36 hours, which is insignificant and leads to a zero exergy efficiency. During mid-season(hours from 1461 to 2920 and from 5841 to 7300), the simultaneous mode is used for simultaneous heating and cooling. The seasonal COP is higher but the seasonal exergy efficiency is lower because of a low Carnot efficiency under mild ambient temperatures. During summer (hours from 2921 to 5840), the cooling mode is used in majority with high COP and higher exergy efficiency. Table 8 finally presents the average annual coefficients of performance and exergy efficiencies. Taking into account the summer and mid-season periods leads to higher coefficients of performance and higher exergy efficiencies. The seasonal or annual values is an average of the values in each mode in proportion to the operating times. The maximum COP is calculated for the simultaneous mode during summer. The maximum exergy efficiency is also reported during summer but in the cooling mode. This difference is due to the higher Carnot efficiency in the cooling mode than in the simultaneous mode.

Table 8: Performance comparison depending on the season

\begin{tabular}{ccccc}
\hline Season & Winter & Mid-season & Summer & Annual \\
\hline Operating time in heating mode $(\mathrm{h})$ & 1374 & 475 & 91 & 1939 \\
Operating time in cooling mode $(\mathrm{h})$ & 36 & 163 & 516 & 714 \\
Operating time in simultaneous mode $(\mathrm{h})$ & 511 & 190 & 77 & 778 \\
Total operating time $(\mathrm{h})$ & 1920 & 828 & 684 & 3431 \\
\hline $\mathrm{COP}_{\text {heating mode }}$ & 2.45 & 2.44 & 2.68 & 2.46 \\
$\mathrm{COP}_{\text {cooling mode }}$ & 3.62 & 3.75 & 3.77 & 3.76 \\
$\mathrm{COP}_{\text {simultaneous mode }}$ & 2.58 & 4.32 & 4.48 & 3.20 \\
$\mathrm{COP}_{\text {seasonal or annual }}$ & 2.51 & 3.13 & 3.71 & 2.90 \\
\hline$\eta_{\text {ex-heating mode }}(\%)$ & $25.5 \%$ & $24.1 \%$ & $18.5 \%$ & $24.8 \%$ \\
$\eta_{\text {ex-cooling mode }}(\%)$ & $0.0 \%$ & $3.5 \%$ & $46.8 \%$ & $34.6 \%$ \\
$\eta_{\text {ex-simultaneous mode }}(\%)$ & $28.2 \%$ & $43.4 \%$ & $22.7 \%$ & $31.3 \%$ \\
$\eta_{\text {ex-seasonal or annual }}(\%)$ & $25.7 \%$ & $24.5 \%$ & $40.3 \%$ & $28.3 \%$ \\
\hline
\end{tabular}




\section{Simulation of HPS2: a heat pump for simultaneous space cooling and desalination}

The studied system links space cooling and desalination demands. Among the principal desalination processes, membrane distillation (MD) seems to be the most suitable for a condensing process because it operates at temperatures compatible with the condenser of a heat pump (Diaby et al., 2017). MD is a process in which a microporous hydrophobic membrane serves as a support for the partial vaporization of the feed fluid (seawater). MD is both a thermal and membrane process. Among the MD configurations, the air gap membrane distillation (AGMD) was chosen for the coupled system because of its simplicity and the lower risk of wettability of the membrane.

\subsection{Presentation of HPS2}

This model applies to office or residential buildings in southern countries where water scarcity is an issue.

Fig. 6 shows the general diagram of the heat pump for simultaneous cooling and desalination HPS2.

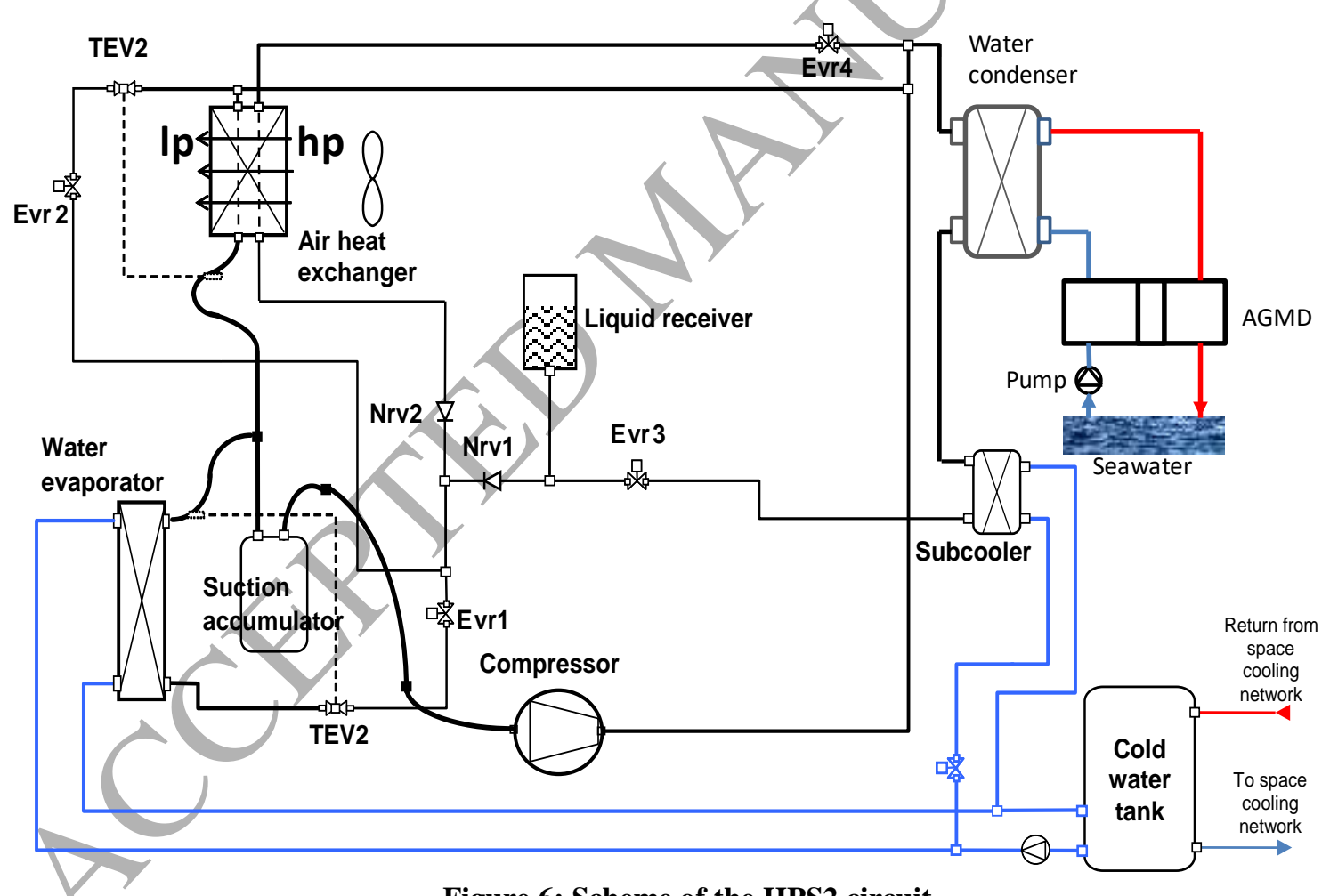

Figure 6: Scheme of the HPS2 circuit

The building is the same hotel of 45 bedrooms now located in Dakar. A heat pump is used to simultaneously produce cold and heat. The heat produced by the heat pump is sent to the desalination unit to produce fresh water. A pump successively drives the seawater in the cold channel of the AGMD unit, in the condenser of the heat pump to heat the seawater, then in the hot channel of the AGMD unit where the flow is divided between the permeate flow and the brine, which is slightly more concentrated in salts. The brine is finally returned to the sea. 
Pre-treatment of feed water and post-treatment of permeate product are not considered in this study. The model developed in the first part for $\mathrm{CO}_{2}$ (HPS1) is coupled with the numerical model of the AGMD unit. The model for distilled water production of the AGMD unit is added to the equation list presented in section 3.2.

\subsection{Specific equations for the AGMD unit}

The performance of a MD module depends on heat and mass transfers. Water is vaporized because of a vapour pressure gradient between the hot channel and the condensation channel. The vapour pressure gradient is created by the temperature difference between the hot and cold feed water. Vapour transfers through a microporous and hydrophobic membrane and condenses on a cold plate (Fig. 7). The permeate flux (J) is proportional to the vapour pressure difference across the membrane and can be determined by Eq. (22). $\mathrm{P}_{1}$ and $\mathrm{P}_{3}$ are the vapour pressures at $\mathrm{T}_{1}$ and $\mathrm{T}_{3}$, determined with Antoine's equation (Eq. (23)).

$J=B\left(p_{1}-p_{3}\right)$

$p=\exp \left(23.1964-\frac{3816.4}{T-44.13}\right)$

$\mathrm{B}$ is the mass transfer coefficient of the membrane, which is only related to the characteristics of the membrane and the gas conditions in the pores of the membrane (Eq. (24)). The porosity $\epsilon$, the tortuosity $\tau$ and the thicknesses $\delta_{\mathrm{m}}$ of the membrane are constants equal to $80 \%, 1.5$ and $0.28 \mathrm{~mm}$ respectively. The thickness of the air gap $\delta_{\mathrm{g}}$ is maintained at $1 \mathrm{~mm}$.

$B=\frac{\epsilon M P D}{R T_{m}\left(\delta_{m} \tau+\delta_{g}\right)\left|p_{a}\right|_{l n, a}}$

Where $\left|p_{a}\right|_{l n}$ is the logarithmic mean pressure of the air in the pores and in the air gap. It is expressed as follows:

$\left|p_{a}\right|_{\ln }=\frac{\left(p_{1}-p_{3}\right)}{\ln \left(\frac{p_{1}}{p_{3}}\right)}$

Finally, the pressure-diffusivity product PD can be calculated as follows (Pangarkar and Deshmukh, 2015):

$P D=1.895 \times 10^{-5} T^{2.027}$

In the AGMD process, heat transfer through the membrane is due to latent heat transfer and sensible thermal conduction. Conservation of energy applies in the different areas of the unit of the AGMD, Eq. (27). Coefficients $\mathrm{hc}_{\mathrm{h}}$ and $\mathrm{hc}_{\mathrm{c}}$ are the convective heat exchange coefficients inside the hot and cold channels respectively.

$\varphi=h c_{h}\left(T_{h}-T_{1}\right)=\frac{\lambda_{m}}{\delta_{m}}\left(T_{1}-T_{2}\right)+J \cdot \Delta h_{e v}=\frac{\lambda_{g}}{\delta_{g}}\left(T_{2}-T_{3}\right)=\frac{\lambda_{p}}{\delta_{p}}\left(T_{3}-T_{4}\right)+J \cdot \Delta h_{c d}=h c_{c}\left(T_{4}-T_{c}\right)$ 
The electric ratio is an indicator generally used for the evaluation of the energy efficiency of thermal desalination units. It is the ratio of the sum of the electric consumptions (compressor and pump) and the volume of distilled water (V) given by Eq. (28).

Electric ratio $=\frac{\dot{W}+\text { electric consumption of the pump }}{V}$

The exergy efficiencies of HPS2 integrate the distilled water production. The first exergy efficiency (Eq. (29)) only takes into account the directly useful productions over the electric exergy consumption. A second exergy efficiency (Eq. (30)) named "process exergy efficiency" integrates all inputs and outputs of HPS2, assuming that each energy and water flows could be possibly exploited.

$\eta_{\text {ex }}=\frac{E x_{\text {th }}+E x_{\text {permeate }}}{E x_{\text {elec }}}$

$\eta_{\text {ex,process }}=\frac{E x_{\text {th }}+E x_{\text {permeate }}+E x_{\text {brine }}}{E x_{\text {elec }}+E x_{\text {seawater }}}$

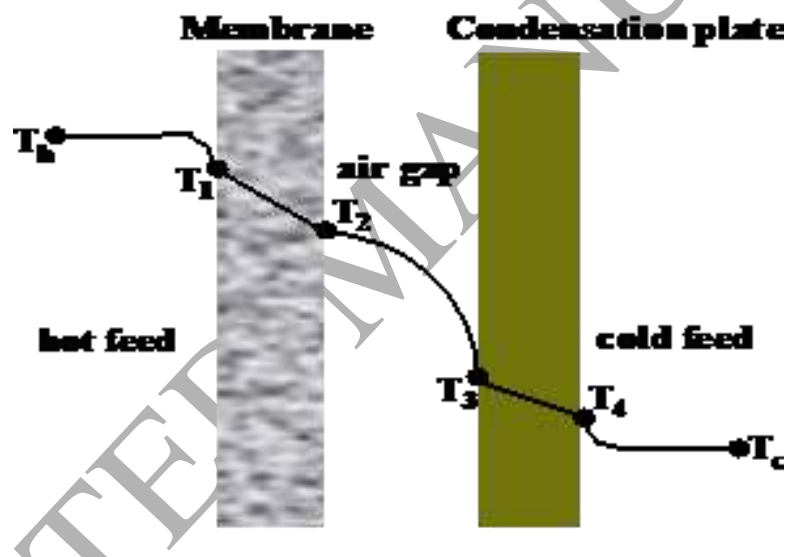

Figure 7: Mechanisms of heat and mass transfers in the AGMD unit

\subsection{Simulation results}

In this study, the behaviour of an installation satisfying cooling needs and production of fresh water according to the climate is studied for the city of Dakar in Senegal. The typology of the building is simulated using TRNSYS software. The multizone building model is used to evaluate the cooling requirements of the hotel. The evolution of outdoor ambient temperature and seawater temperature is shown in Fig. 8. The weather data files are the ones used in TRNSYS software (SEL, 2000) simulating a typical meteorological year. The climate of Dakar is tropical with an annual average temperature of $24.5^{\circ} \mathrm{C}$. 


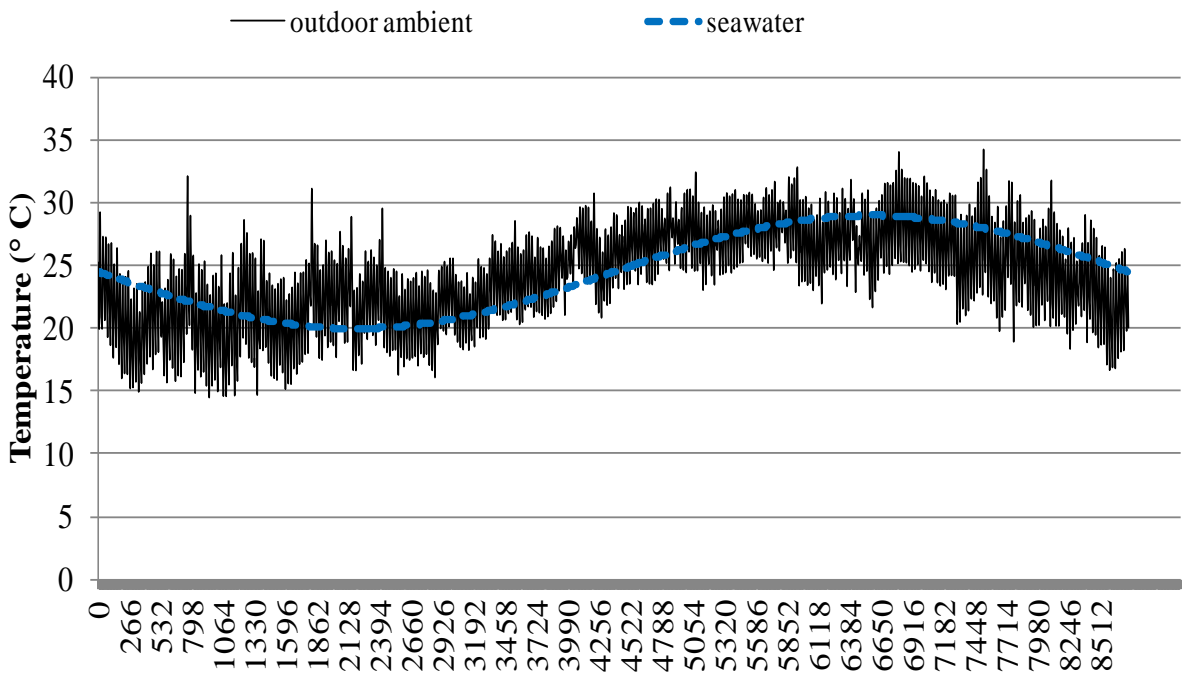

Simulation time (h)

Figure 8: Evolution of outdoor ambient and seawater temperatures

Buildings in warm regions have high needs for cold and fresh water. Fig. 9 shows the evolution of the hotel building needs in cooling during a year. It can be seen that cooling needs are an important part of energy needs. The annual needs of the hotel count for $237886 \mathrm{kWh} / \mathrm{year}$ in cooling. The needs for cooling are very high between June and November because it is a hot period. This also leads to a higher demand for water during this period. Nevertheless, the presence of simultaneous demand for fresh water and cooling stays high all over the year.

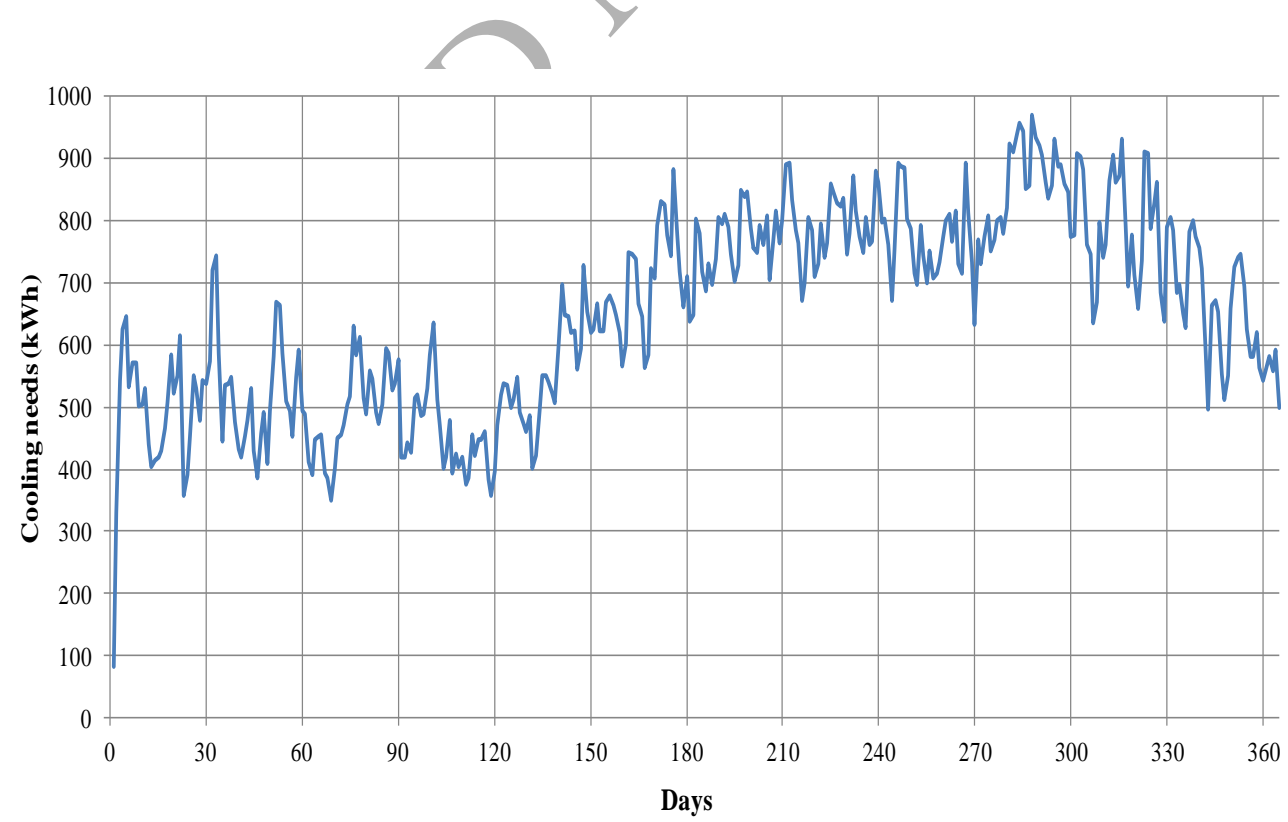

Figure 9: Evolution of daily needs in cooling of a hotel in Dakar

An optimization study is performed beforehand to identify the optimal flow from the seawater feed pump to the system. The Min/Max command of EES is used to optimize the efficiency through a genetic optimization 
method. This function highlights two peaks. A traditional optimization algorithm would likely be attracted to the broader peak, although it represents a preferred local optimum (Klein, 2017). The genetic algorithm correctly identifies the global optimum. It has been noticed in other works that low flow rates significantly decrease the performance of the heat pump (Diaby et al., 2017). The optimum flow rate is $9.8 \mathrm{l} / \mathrm{min}$, this value is fixed in the next simulations.

Fig. 10 illustrates the production of permeate flux and the instantaneous coefficient of performance $\left(\mathrm{COP}_{\text {inst }}\right)$. The permeate flux and $\mathrm{COP}_{\text {inst }}$ are very sensitive to the variation of the seawater temperature that feeds the AGMD unit. Indeed, the permeate stream is greater when the temperature of seawater is high. This observed increase in permeate flux is due to the increase in the driving force of the transfer (the transmembrane vapour pressure gradient) as the condenser seawater outlet temperature increases. The evolution of this seawater outlet temperature of the gas cooler or evaporator temperature of seawater is shown in Fig. 11. It was demonstrated that the effect of the condensation temperature in the cold channel of the AGMD is less important compared to the evaporation temperature of the hot channel seawater (Khalifa et al., 2015). On the other hand an increase of the temperature of the seawater supply in the cold channel of the MD unit reduces the $\mathrm{COP}_{\text {inst. }}$ A decrease of the $\mathrm{COP}_{\text {inst }}$ penalizes the operation of the heat pump by increasing the energy consumption of the compressor for the same cooling power.

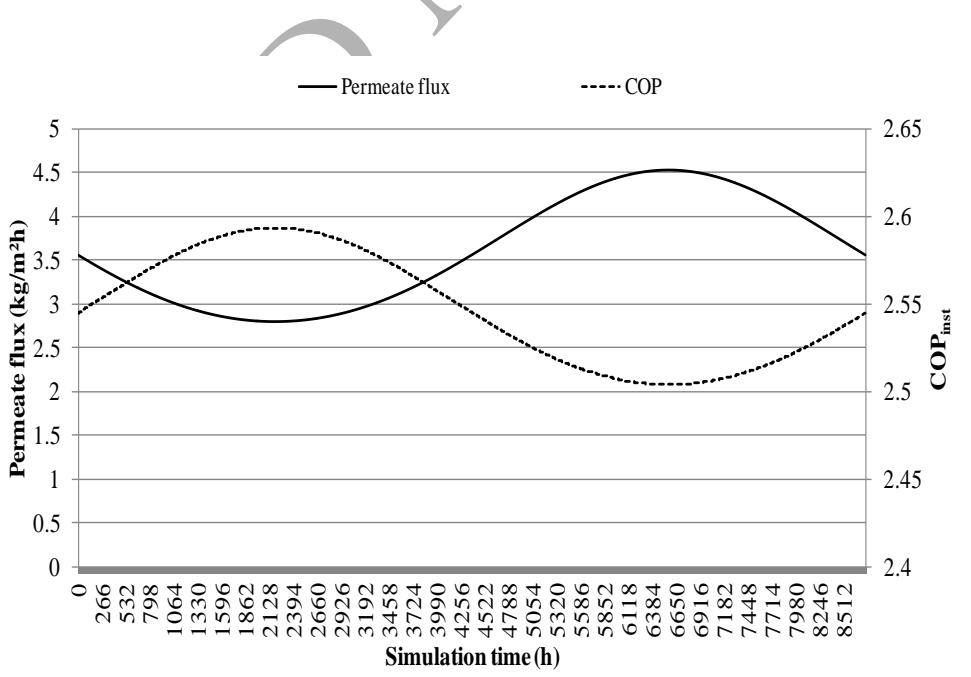

Figure 10: Evolution of permeate flux and $\mathrm{COP}_{\text {inst }}$ 


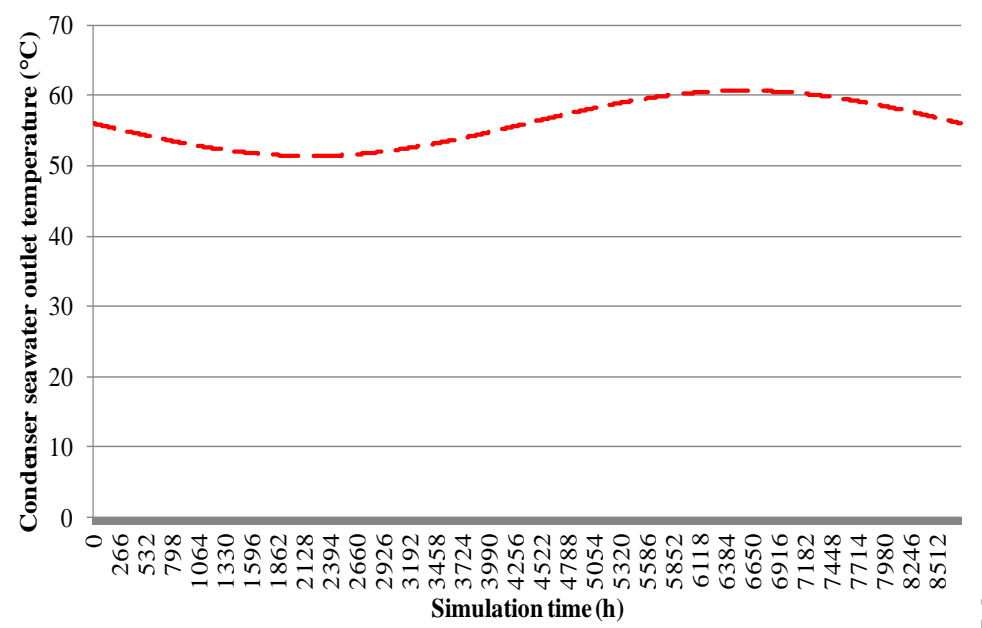

Figure 11: Evolution of the seawater outlet temperature of the condenser/gas cooler

The evolution of the water production and the electrical ratio during a less hot day (temperature varying between 14.65 and $22.07^{\circ} \mathrm{C}$ ) are presented in Fig. 12. This choice is justified by the fact that the COP of HPS2 is higher when outside temperatures (ambient air and seawater) are low as shown in Fig. 8. This day corresponds to the date of February $15^{\text {th }}$. The highest water production was observed at 14:00. Indeed, at this time of day, the outside temperatures are maximum which explains this increase of the production of water. The minimum electrical ratio is obtained at that time of the day. These calculated electric ratio values are very close to those found by the authors at reference (Byrne et al., 2015). During this day the production of water varied between 12 and $23 \mathrm{l} / \mathrm{h}$.

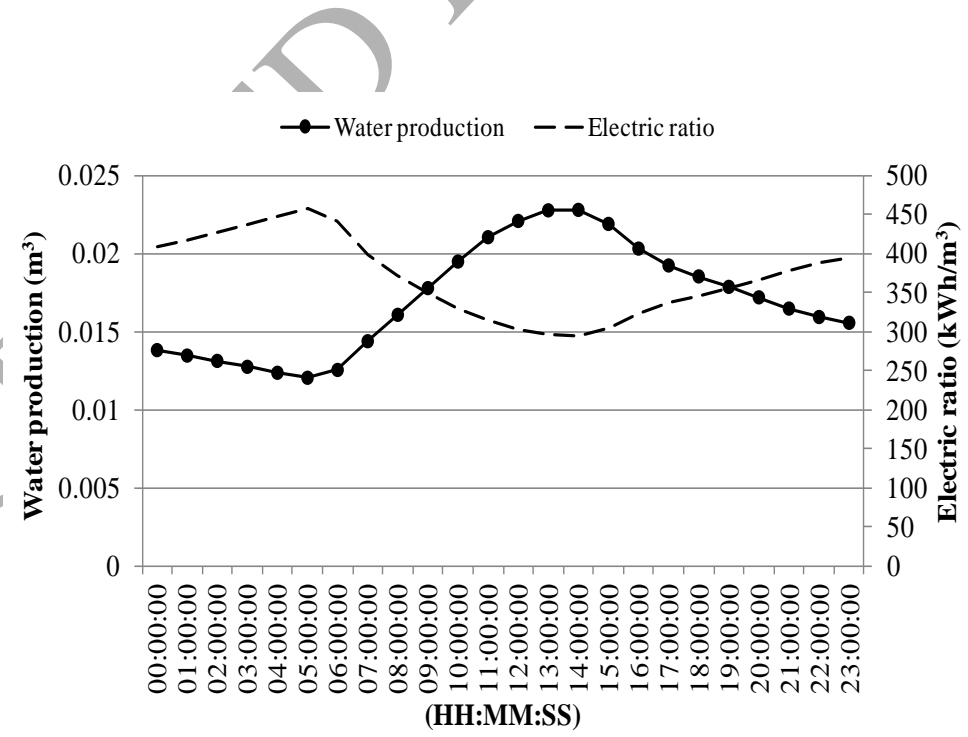

Figure 12: Evolution of distilled water production and electric ratio during a day

Table 9 shows the coefficient of performance, the exergy efficiency and the annual distilled water production. The coefficient of performance is close to that obtained with HPS1 even if the plant regions are different (only - 
$12.4 \%$ decrease). The COP of HPS1 is an integrated heating and cooling COP whereas HPS2 has a COP in cooling only. The quite satisfactory cooling COP benefits from the good use of energy for the membrane distillation application. The exergy efficiency is lower (by -26.1\%) for the coupling of the heat pump and the desalination unit because of the low exergy in the case of desalinated water production compared to hot water for space heating or domestic hot water. The process exergy efficiency of HPS 2 is higher by $+12.2 \%$. It assumes that all the energy and water flows have values. This result reveals that an amount of energy should be recovered in the brine. The quantity of water produced by this system contributes to $12.8 \%$ of the hotel's freshwater demand, corresponding to an annual water consumption estimated at around $2464 \mathrm{~m}^{3} /$ year (e.g. 150 litres per day and per bedroom).

Table 9: Annual performance of HPS2 vs HPS1

\begin{tabular}{cccc}
\hline Performances & HPS2 & HPS1 & Relative difference (\%) \\
\hline $\boldsymbol{C O P}_{\text {seaonal }}$ & 2.54 & 2.90 & $-12.4 \%$ \\
\hline $\boldsymbol{\eta}_{\text {ex-seasonal }}(\boldsymbol{\%})$ & $20.9 \% / 31.8 \% *$ & $28.3 \%$ & $-26.1 \% /+12.2 \% *$ \\
\hline Water production $\left(\mathbf{m}^{3} /\right.$ year $)$ & 316.53 & 0 & - \\
\hline & $*$ process exergy efficiency &
\end{tabular}

\section{Conclusions}

In this paper, the numerical model of a heat pump using $\mathrm{CO}_{2}$ in a transcritical cycle was used for simultaneous cooling and space heating, DHW production or desalination. The following conclusions can be stated.

- The results are as interesting in temperate regions as in warm regions with desalination.

- In the study of HPS1, a low exergy efficiency is noticed with a $\mathrm{CO}_{2}$ heat pump because of the poor performance in the cooling mode. However, it increases in domestic hot water production mode taking into account the space heating auxiliaries.

- The HPS2 study shows that desalination is really interesting with $\mathrm{CO}_{2}$ due to the high temperature variation in the gas cooler. HPS2 is a system that can reduce emissions of greenhouse gases and the cost of freshwater in hotels in hot regions.

- The simulations show interesting performance indicators for both systems: seasonal COP for heating and cooling and exergy efficiency. They have a relatively close annual COP. HPS2 has a lower exergy efficiency than HPS1, but a higher one when including all inputs and outputs of the process. The quantity of water produced by system HPS 2 contributes to $12.8 \%$ of the hotel's water needs. 
- $\mathrm{CO}_{2}$ is interesting for multi-function heat pumps because it can propose new coupled applications that would be less efficient with standard refrigerants.

\section{Acknowledgements}

The authors would like to acknowledge the BPO foundation and the Regional Council of Brittany for their financial support.

\section{References}

Adriansyah, W., 2004. Combined air conditioning and tap water heating plant using CO2 as refrigerant. Energy Build. 36, 690-695.

Agrawal, N., Bhattacharyya, S., 2011. Experimental investigations on adiabatic capillary tube in a transcritical $\mathrm{CO} 2$ heat pump system for simultaneous water cooling and heating. Int. J. Refrig. 34, 476-483.

ASHRAE, 1989. ASHRAE Handbook Fundamentals (SI Edition), Edition of the American Society of Heating, Refrigerating and Air-Conditioning Engineers.

Bansal, P., 2012. A review - Status of $\mathrm{CO} 2$ as a low temperature refrigerant: Fundamentals and R\&D opportunities. Appl. Thermal Eng. 41, 18-29.

Bennett, D.L., Chen, J.C., 1980. Forced convection boiling in vertical tubes for saturated pure components and binary mixtures. Journal of AIChE 26, 454-461.

Byrne, P., Miriel, J., Lenat, Y., 2009. Design and simulation of a heat pump for simultaneous heating and cooling using HFC or CO2 as a working fluid.Int J Refrig, 32, 1711-1723.

Byrne, P., Miriel, J., Lenat, Y., 2011. Experimental study of an air-source heat pump for simultaneous heating and cooling - part 2: dynamic behaviour and two-phase thermosiphon defrosting technique. Appl. Energy $88,3072-3078$.

Byrne, P., Miriel, J., Lenat, Y., 2012. Modelling and simulation of a heat pump for simultaneous heating and cooling. Build. Simul. 5 (3), 219-232.

Byrne, P., Fournaison, L., Delahaye, A., Ait Oumeziane, Y., Serres, L., Loulergue, P., Szymczyk, A., Mugnier, D., Malaval, J.-L., Bourdais, R., Gueguen, H., Sow, O., Orfi, J., Mare. T., 2015. A review on the coupling of cooling, desalination and solar photovoltaic systems. Renew. Sustain. Energy Rev. 47, 703-717.

Chesi, A., Ferrara, G., Ferrari, L., Tarani, F., 2012. Setup and characterisation of a multi-purpose test rig for R744 refrigerating cycles and equipment, Int. J. Refrig. 35, 1848-185.

Diaby, A.T., Byrne, P., Loulergue, P., Balannec, B., Szymczyk, A., Maré, T., Sow. O., 2017. Design study of the coupling of an air gap membrane distillation unit to an air conditioner. Desalination 420 (2017) 308-317.

European Standard, 2013. EN 14511: Air conditioners, liquid chilling packages and heat pumps with electrically driven compressors for space heating and cooling.

Farsi, A., Mohammadi, S.M.H., Ameri, M., 2016. An efficient combination of transcritical CO2 refrigeration and multieffect desalination: Energy and economic analysis. Energy Convers. Manag. 127, 561-575. 
Fernandez, N., Hwang, Y., Radermacher, R., 2010. Comparison of CO2 heat pump water heater performance with baseline cycle and two high COP cycles. Int. J. Refrig. 33, 635 - 644.

Gnielinski, V., 1976. New equations for heat and mass transfer in turbulent pipe and channel flows. Int. Chem. Eng. 16, 359-368.

Gullo, P., Hafner, A., Banasiak, K., 2018. Transcritical R744 refrigeration systems for supermarket applications: Current status and future perspectives, Int. J. Refrig. 93, 269-310.

Haida, M., Smolk, J., Hafner, A., Palacz, M., Banasiak, K., Nowak, A.J., 2018. Modified Homogeneous relaxation model for the R744 trans-critical flow in a two-phase ejector. Int. J. Refrig. 85, 314-333

Hu, B., Li, Y., Cao, F., Xing, Z., 2015. Extremum seeking control of COP optimization for air-source transcritical CO2 heat pump water heater system. Appl. Energy 147, 361-372.

Hwang, Y., Kim, B.H., Radermacher. R., 1997. Boiling heat transfer correlation for carbon dioxide IIF-IIR Commission B1, with E1\&E2, College Park (MD, USA), 81-95.

Jiang, Y., Ma, Y., Li, M., Fu, L., 2013. An experimental study of trans-critical CO2 water-water heat pump using compact tube-in-tube heat exchangers. Energy Convers. Manag. 76, 92-100.

Khalifa, A., Lawal, D., Antar, M., Khayet, M., 2015. Experimental and theoretical investigation on water desalination using air gap membrane distillation. Desalination 376, 94 - 108.

Klein, S., 2017. Engineering Equation Solver, Version 10.200-3D, (C1992-2017.

Liu, Y., Groll, E.A., Yazawa, K., Kurtulus, O., 2016. Theoretical analysis of energy-saving performance and economics of $\mathrm{CO} 2$ and $\mathrm{NH} 3$ heat pumps with simultaneous cooling and heating applications in food processing. Int. J. Refrig. 65, 129-141.

Llopis, R., Nebot-Andrés, L., Cabello, R., Sánchez, D., Catalán-Gi, J., 2016. Experimental evaluation of a CO2 transcritical refrigeration plant with dedicated mechanical subcooling. Int. J. Refrig. 69, 361-368.

Lorentzen, G., 1994. Revival of carbon dioxide as a refrigerant. Int. J. Refrig. 17 (5), 292-301.

Ma, Y., Liu, Z., Tian, H., 2013. A review of transcritical carbon dioxide heat pump and refrigeration cycles. Energy 55, 156-172.

Macedonio, F., Drioli, E., 2010. An exergetic analysis of a membrane desalination system. Desalination 261, 293-299.

Nekså, P., 2002. CO2 heat pump systems, Int. J. Refrig. 25 (4), 421-427.

Pangarkar, B.L., Deshmukh. S.K., 2015. Theoretical and experimental analysis of multi-effect air gap membrane distillation process (ME-AGMD). J. Environmental Chem. Eng. 3, 2127-2135.

Peñarrocha, I., Llopis, R., Tárrega, L., Sánchez, D., Cabello, R., 2014. A new approach to optimize the energy efficiency of CO2 transcritical refrigeration plants. Appl. Thermal Eng. 67, 137-146.

Pitarch, M., Navarro-Peris, E., Gonzalvez, J., Corberan, J.M., 2016. Analysis and optimisation of different twostage transcritical carbon dioxide cycles for heating applications. Int. J. Refrig. 70, 235-242.

Pitla, S.S., Groll, E.A., Ramadhyani, S., 2002. Correlation to predict the heat transfer coefficient during in-tube cooling of turbulent supercritical CO2. Int. J. Refrig. 25 (7), 887-895. 
Sánchez, D., Patiño, J., Sanz-Kock, C., Llopis, R., Cabello, R., Torrella, E., 2014. Energetic evaluation of a CO2 refrigeration plant working in supercritical and subcritical conditions. Appl. Thermal Eng. 66, 227-238.

Sawalha, S., 2013. Investigation of heat recovery in $\mathrm{CO} 2$ trans-critical solution for supermarket refrigeration. Int. J. Refrig. 36, 145-156.

Sian, R.A., Wang, C.-C., 2017. Constraints-free modeling and experimental validation of a transcritical CO2 system for medium and large scale applications. Appl. Thermal Eng. 124, 136-151.

Solar Energy Laboratory, University of Wisconsin-Madison, TRNSYS, A Transient Simulation Program, 2000, Volume I, Reference Manual.

Tran, T.N., Wambsganss, M.W., France, D.M., 1996. Small Circular and Rectangular-Channel Boiling with Two Refrigerants, Int. J. Multiphase Flow, 22 (3), 485-498.

White, S.D., Cleland, D.J., Cotter, S.D., Stephenson, R.A., Kallu, R.D.S, Fleming, A.K., 1997. A heat pump for simultaneous refrigeration and water heating. IPENZ Trans 1997, 24.

Yang, L., Li, H., Cai, S.W. Shao, L.L., Zhang, C.L., 2015. Minimizing COP loss from optimal high pressure correlation for transcritical CO2 cycle. Appl. Thermal Eng. 89, 656-662. 